\title{
Sexual activity in macropterous and brachypterous males of a flightless bug, Pyrrhocoris apterus (Heteroptera)
}

\author{
RADOMÍr SOCHA*, JAN ŠULA and DALIBOR KODRÍK \\ Institute of Entomology, Academy of Sciences, Branišovská 31, CZ-370 05 České Budějovice, Czech Republic
}

Key words. Firebug, adult males, wing morphs, sexual activity, mating, fasting, diapause, accessory glands, immunoblotting

\begin{abstract}
The long-winged (macropterous) and short-winged (brachypterous) adult males of Pyrrhocoris apterus (L.) from temperate (Czech Republic) and Mediterranean (Israel) populations were analysed for the sexual activity and the functional activity of their accessory glands. The sexual activity of the males reared either under long-day (18L : 6D) or short-day (12L : 12D) conditions was determined by their capability to mate with 5-day-old reproductive females of the brachypterous morph and to fertilize the eggs. The functional activity of accessory glands was characterized by the presence of a specific immuno-marker. Sexual activity of fasting macropterous males from both temperate and Mediterranean populations was almost as high as that observed in the reproductive brachypterous ones. These findings were also confirmed by an immunotest. Contrary to the temperate macropterous males, the feeding arrest in temperate macropterous females was coupled with a non-diapause inhibition of reproduction in spite of long days. A similar kind of difference was observed also in the Mediterranean macropterous bugs reared under short-day conditions. The results showed the sexual difference in reproductive activity of the macropterous morph in P. apterus.
\end{abstract}

\section{INTRODUCTION}

The firebug, Pyrrhocoris apterus (Linnaeus, 1758) is a convenient experimental model for biological research (see review Socha, 1993). Short-winged (brachypterous) and long-winged (macropterous) specimens may be produced (Seidenstücker, 1953; Tischler, 1959; Honěk, 1976) and two generations develop per year in the Czech Republic in warmer years and places (Socha \& Šula, 1992). The wing dimorphism and diapause of this flightless heteropteran species are genetically determined but influenced by environmental variables, mainly by photoperiod and temperature (Socha, 1993). Under constant short-day conditions (photophase $<16 \mathrm{~h}$ ), all bugs from temperate population become brachypters and enter diapause (Hodek, 1968; Saunders, 1983), while under longer days the bugs do not diapause and a fraction of population becomes macropterous (Honěk, 1976). There is a latitudinal gradient in the wing-form response of $P$. apterus to photoperiod with the critical daylength 12.5 and $16.5 \mathrm{~h}$ of light in the Mediterranean (Israel) and temperate (Czech Republic) population, respectively (Socha, 2001). The critical daylength for determination of diapause in this bug was also $4-5 \mathrm{~h}$ shorter in Mediterranean population than in the temperate one (Socha \& Šula, 1996; Socha, unpubl.). Geographical differences in photoperiodic response regulating wing length and diapause, an occurrence of wing morph-specific types of reproductive arrest in females (Socha \& Šula, 1996) and higher adipokinetic and locomotory activities in macropters than in brachypters (Kodrík \& Socha, 1999; Socha \& Kodrík, 1999; Socha \& Zemek, 2001) indicate that macropterous morph might play a specific role in the life strategy of this heteropteran, most probably in its dispersal.
The adult life of $P$. apterus males may last from two months to one year, depending mostly on their sexual activity. In males, sexual behaviour was studied only in the specimens of brachypterous morph (Žd'árek, 1967, 1968, 1970; Zachardová et al., 1989; Hodková et al., 1991; Hodková, 1994). Non-diapausing males start to mate 3 to 5 days after the imaginal ecdysis; in males the sexual activity does not fluctuate throughout the imaginal life. Whereas in females the overall physiology is deeply affected by diapause (Sláma, 1964a), in males the absence of mating behaviour is probably the most significant character of a diapausing specimen. The diapause in males was presumed not to be easily characterized using other physiological criteria (Sláma, 1964b). However, further studies revealed that diapause of brachypterous males can be recognized also by means of other specific markers, e.g. by the accumulation of hexameric storage protein in the haemolymph (Šula et al., 1995; Socha \& Šula, 1996) and the absence of particular proteins in their accessory glands (AG) (Šauman \& Sehnal, 1997).

Recent research showed that, contrary to brachypters, the macropterous females from temperate population may enter two different types of reproductive arrest, i.e. that of non-diapause type under a long-day photoperiod, and hibernal diapause induced by a short-day photophase (Honěk, 1985; Socha \& Šula, 1996; Šula et al., 1998). Thus, the macropterous specimens of the temperate population of $P$. apterus can distinguish between two daylengths thresholds, inducing either hibernal diapause or reproductive arrest of non-diapause type. While the hibernal diapause in brachypterous bugs of both sexes is characterized by a very high level of the hexameric proteins in haemolymph, its content in haemolymph of macropterous males and females is at most as low as in the

\footnotetext{
* Corresponding author: e-mail: Socha@entu.cas.cz
} 
reproductive adults. In both the long-day temperate and short-day Mediterranean macropterous females the reproductive arrest of non-diapause type is characterized by prolonged pre-oviposition period (Socha \& Šula, 1996). Two possible interpretations of the extended preoviposition period and occurrence of non-diapause reproductive arrest in macropterous females were proposed. It might either represent a relict of a summer diapause (aestivation) or be associated with macroptery and relate to the migratory activity of the macropterous morph rather than to photoperiodically induced diapause (Socha \& Šla, 1996). When the second interpretation is valid, then the macropterism-associated reproductive arrest can represent a relict of "oogenesis-flight" syndrome (Johnson, 1969). In spite of the above findings, data concerning the reproductive activity in the macropterous males of $P$. apterus are missing.

Since the wing dimorphism has been discussed with allocation of reproduction and dispersal in flying insects and most results so far are restricted to females of these species (Zera \& Denno, 1997), the aim of the present study was to describe the relationship between wing morphs and reproduction in males of non-flying species. The relationship between wing morphs and reproduction in insects with a nonfunctional wing dimorphism (i.e. with non-flying macropters) is of great interest. The present paper was focused therefore on the comparison of the sexual activity of macropterous males with that of the brachypterous ones and finding whether the reproductive arrest of non-diapause type occurs also in the macropterous males from temperate (Czech Republic) and Mediterranean populations (Israel).

\section{MATERIAL AND METHODS}

\section{Experimental animals}

The laboratory stock cultures of $P$. apterus were reared on linden seeds and water at temperature $26 \pm 1^{\circ} \mathrm{C}$. The temperate (T) cultures producing specimens of brachypterous and macropterous morphs were established from the bugs collected at Ceské Budějovice (Czech Republic, $49^{\circ} \mathrm{N}$ ) and bred under a constant photoperiod of $18 \mathrm{~h}$ light-6 h dark (Socha et al., 1997; 1998) Water and linden seeds were replenished twice a week. The long-day conditions are known to prevent diapause and allow continuous breeding. The animals of $\mathrm{T}$ culture destined for diapause were kept from eggs until adult stage under a constant short-day (12L : 12D) photoperiod. The wild-type diapausing males of brachypterous morph were collected from the field (České Budějovice) in the second half of October. The standard Mediterranean culture (M), originating from Ma'agal Michael (Israel, $33^{\circ} \mathrm{N}$ ) population, was reared under a constant photoperiod of $16 \mathrm{~L}: 8 \mathrm{D}$. The highest proportion of macropters in $\mathrm{M}$ culture was induced under a photoperiod of 12L : 12D (at $26 \pm$ $1^{\circ} \mathrm{C}$ ) (Socha \& Š Sula, 1996; Socha, 2000). To obtain sufficient number of macropterous males for our experiments we transferred the eggs laid by females from the $M$ culture in a photoperiod of $16 \mathrm{~L}: 8 \mathrm{D}$ to a photoperiod of $12 \mathrm{~L}: 12 \mathrm{D}$ and allowed them to develop in these conditions at $26 \pm 1^{\circ} \mathrm{C}$ until the adult stage.

Freshly ecdysed adult males of a particular wing morph removed from $\mathrm{T}$ and $\mathrm{M}$ cultures were transferred into small glass jars $(0.251)$ in groups of $10-15$ specimens and kept under the same photoperiodic regimen, in which they developed.
When they were 10 days old, they were individually used for experiments.

The experimental groups of adult males were marked as follows: temperate population - reproductive brachypters (T-br-R), diapausing brachypters from the laboratory (T-br- $\mathrm{D}_{\mathrm{L}}$ ) and the field (T-br- $\mathrm{D}_{\mathrm{N}}$ ), and macropters (T-ma); Mediterranean population - brachypters (M-br) and macropters (M-ma).

\section{Sample preparation and electrophoresis}

Electrophoretic analysis of the accessory gland (AG) proteins was performed using 1, 5, and 10 days old adult males; ten specimens were analysed in each experimental group. The AG were dissected out from the body and individually homogenised in $15 \mu \mathrm{l}$ of the sample buffer $(0.06 \mathrm{M}$ Tris, $0.5 \%$ dithiothreitol, $8.54 \mathrm{M}$ urea and $2 \%$ SDS; $\mathrm{pH}$ adjusted to 6.8 by HCl). Simultaneously the condition of the midguts was inspected. After homogenization in an Eppendorf micro tube at 2,000 rpm and centrifugation at $10,000 \mathrm{~g}$ for $10 \mathrm{~min}$ the supernatants were used. Aliquots of $0.4 \mathrm{AG}$ were taken for the polyacrylamide gel electrophoresis under denaturing conditions (in SDS) according to Laemmli (1970) on 5-20\% gradient slab gels $0.7 \mathrm{~mm}$ thick. Molecular weight markers were purchased from Pharmacia LKB. The gels with separated proteins were used for immunoblotting.

\section{Immunoblotting methods}

AG proteins separated by PAGE were electroblotted onto nitrocellulose membrane $(0.45 \mu \mathrm{m}$ pore, Schleicher \& Schuell) according to Towbin et al. (1979) using a wet blotter (Hoeffer Scientific Instruments). Five per cent Skim Milk dissolved in phosphate-buffered saline containing $0.5 \%$ Tween 20 (PBSTween) was used to saturate nonspecific binding sites. Nitrocellulose sheets were then overlaid with the first monoclonal antibody solution (dilution 1:50,000 in PBS-Tween) and incubated for $1 \mathrm{~h}$ at room temperature.

This monoclonal antibody PL - 15.2 was kindly provided by G.M. Happ (University of Vermont). It was originally raised against a secretory $80-90 \mathrm{kDa}$ antigen from tubular $\mathrm{AG}$ of the adult mealworm T. molitor (Grimness \& Happ, 1986) and its nomenclature, specificity and immunohistochemical application to $P$. apterus was described by S̆auman \& Sehnal (1997). The antibody gives a positive reaction with an AG protein from the reproductive adult males of $P$. apterus.

Antigen-antibody complexes were visualized by means of another reaction with second antibody SwAM/Px (swine antimouse immunoglobulin labelled with horseradish peroxidase, Sevac Praha) diluted 1:1000 in PBS-Tween and kept for $1 \mathrm{~h}$ at room temperature. The substrate for peroxidase, 3,3-diaminobenzidine tetrahydrochloride, was dissolved in $0.1 \mathrm{M}$ Tris- $\mathrm{HCl}$ buffer, $\mathrm{pH} 7.0$, and the reaction continued in the presence of hydrogen peroxide for 1-2 min.

\section{Mating and fertility tests}

The mating tests were carried out in Petri dishes $(6 \mathrm{~cm}$ in diameter). Usually a set of about 8 dishes was observed simultaneously. Thirty-two to forty-four males of each experimental group (T-br-R; T-br-D ; T-ma; M-br; M-ma), 10 days old, were tested for their mating activity. They were individually tested in isolated couples in each dish (the isolated-couple test) with 5-day-old reproductive virgin females of brachypterous morph; females of this age had very high attractiveness and receptivity (cf. Žd'árek, 1967). The test consisted of one 30 min observation period. In each experimental group, the number of males with successful courtship completed by the connection (copulation) was recorded.

Fertility of 10-day-old macropterous males was determined based on their capability to fertilize the eggs laid by reproduc- 
tive females of the brachypterous morph. The fertility test was also carried out in $6 \mathrm{~cm}$ Petri dishes. Ten macropterous and reproductive brachypterous males were tested in isolated couples. Ten days later the males were removed and each female kept individually to lay three consecutive egg batches; fertilization of eggs was subsequently evaluated.

\section{Figure preparation and statistical analysis}

The pictures of representative blots for 1,5 and 10 days old males of five experimental groups were digitalized by a gel documentation system (White/Ultraviolet transilluminator, UVP) and resulting images in TIFF format were subjected to densitometry. The programme "Quantiscan" (Microbial Systems Ltd. 1991, distributed by BIOSOFT) was used for quantitative evaluation of immunopositive bands. The integrated areas across the corresponding peaks were compared and expressed as relative numbers.

The graphs were made by means of the software GraphPad Prism, version 3.0 (San Diego, CA, USA). Statistical evaluation of results was performed using t-test (hatchability of eggs) or the contingency tables followed by Fisher's exact test (mating activity) or Chi-square test (food content in midguts).

\section{RESULTS}

\section{Immunoblotting}

On the first day of adult life the immunoreaction in all experimental groups of males was almost negligible (Fig. 1), while conspicuous reactions of similar intensities were shown in the reproductively active brachypterous and macropterous males from both temperate and Mediterranean populations on days 5 and 10 . On the other hand, immunoblotting of $\mathrm{AG}$ proteins after SDS-PAGE revealed almost no reaction of the antibody in the homogenates of laboratory and field-collected diapausing males of the temperate population. The quantitative estimate of the intensities of immunoreactions showed (a) the rise of intensity in all experimental groups (except of field-collected diapausing males), and (b) this increase (between day 1 and 5) was very steep in males of all groups except laboratory and field-collected diapausing brachypters (Fig. 2). This resulted in either steadily low levels of the antigen in diapausing brachypterous males, or 5 to 6 times higher levels in other groups at days 5 and 10 .

\section{Mating and fertility}

Analysis of mating behaviour showed a distinct difference in mating activity between diapausing brachypterous males and males of other experimental groups (Fig. 3). The lowest percentage $(2.5 \%)$ of mating males was observed in the diapausing laboratory brachypterous group. On the other hand, the percentage of mating in the macropterous males from the temperate $(89.5 \%)$ and Mediterranean $(82.5 \%)$ populations was only slightly lower than that in the temperate and Mediterranean brachypterous males $(97.7 \%$ and $93.8 \%$, respectively).

Fertility tests of long-day reared macropterous and reproductive brachypterous males mated with 5-day-old reproductive adult females of the brachypterous morph showed almost no differences in fertilization of three successive egg batches laid by these females. Hatchability of eggs was as high as $80.0 \pm 22.2 \%$ and $85.9 \pm 11.0 \%$ in case of macropterous and brachypterous males, respectively. The difference was statistically non-significant $(P$ $=0.537$ ).

Dissection of midguts revealed high amounts of food in the reproductive brachypterous males, much lower quantities in the diapausing laboratory brachypters and no food in the macropterous males and field-collected diapausing males of the brachypterous morph (Table 1). All

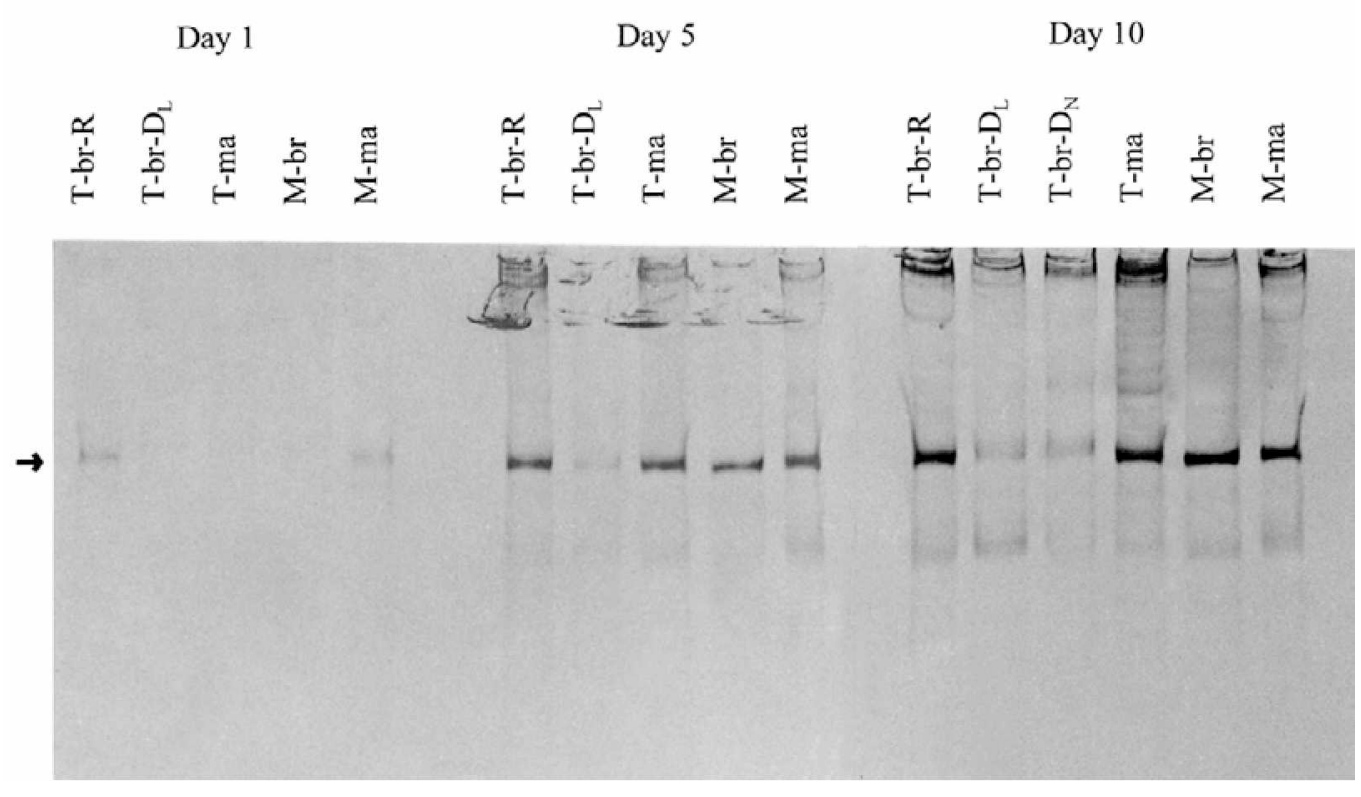

Fig. 1. Immunoblotting of AG proteins in 1, 5 and 10 days old males after SDS-PAGE: 1 - T-br-R; 2 - T-br-D $\mathrm{D}_{\mathrm{L}} ; 3$ - T-br-D T-ma; 5 - M-br; 6 - M-ma. The arrow indicates the position of a detected antigen. For abbreviations see Material and Methods. 


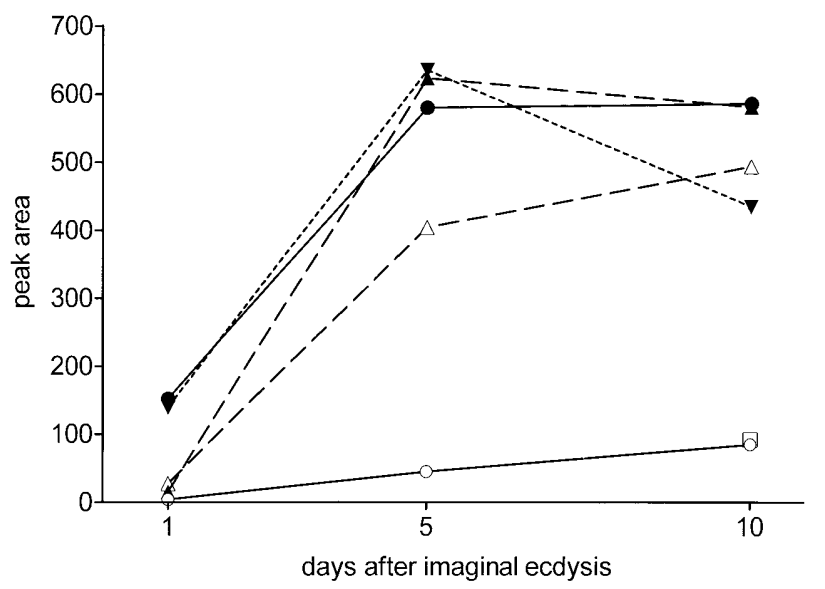

Fig. 2. The typical picture of changes in quantity of the antigen in AG detected by PL 15.2 antibody in 1, 5 and 10 days old males of all experimental groups. The quantity is expressed as the area of the peak after densitometry evaluation of the immunoblot (Fig. 1). Symbols used: • T-br-R, O T-br- $D_{\mathrm{L}}$, $\square \mathrm{T}$-br- $\mathrm{D}_{\mathrm{N}}, \Delta \mathrm{M}$-br, $\Delta \mathrm{T}$-ma, $\mathbf{} \mathrm{M}$-ma. For abbreviations see Material and Methods.

the results showed that mating activity and fertility of macropterous males of both populations were not inhibited by the fact that they refused feeding.

\section{DISCUSSION}

It is known that a hexameric storage protein $\left(M_{\mathrm{r}} \sim\right.$ $480,000)$ accumulates in a high quantity in the haemolymph of diapausing adults, while its amount in nondiapausing reproductive bugs is negligible (Šula et al., 1995). We found an absence or very low concentration of this protein also in the haemolymph of the macropterous females of both temperate and Mediterranean populations during their reproductive arrest (Socha \& Sula, 1996).

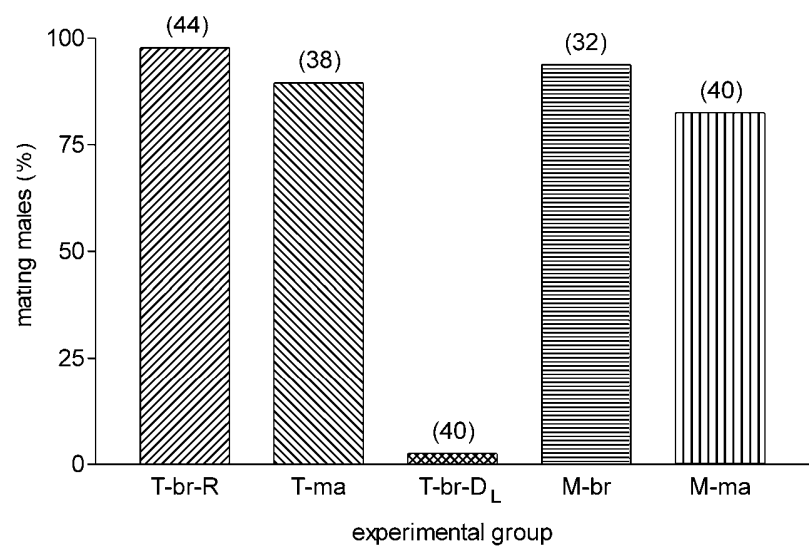

Fig. 3. Mating activity of 10-day-old adult males of five different experimental groups individually kept in single couples with 5-day-old reproductive adult females of brachypterous morph. Numbers of males in experimental groups are shown in parentheses above the bars. The Fisher's exact test revealed that reproductive and diapausing brachypterous males were significantly different $(P<0.0001)$, while there were no significant differences between reproductive brachypterous and macropterous males both in Mediterranean $(P=0.282)$ and temperate $(P=0.569)$ populations. For abbreviations see Material and Methods.
TABLE 1 . The presence of food in midguts of adult males of $P$. apterus.

\begin{tabular}{lccccc}
\hline $\begin{array}{l}\text { Experi- } \\
\text { mental } \\
\text { group }\end{array}$ & $\begin{array}{c}\text { Rearing } \\
\text { photo- } \\
\text { period }\end{array}$ & $\begin{array}{c}\text { Number } \\
\text { of males } \\
\text { analysed }\end{array}$ & $\begin{array}{c}\text { Midgut } \\
\text { with food } \\
\%(n)\end{array}$ & $\begin{array}{c}\text { Midgut half- } \\
\text { or near-empty } \\
\%(n)\end{array}$ & $\begin{array}{c}\text { Midgut } \\
\text { without food } \\
\%(n)\end{array}$ \\
\hline T-br-R & 18L:6D & 17 & $94.1(16)$ & $0(0)$ & $5.9(1)$ \\
T-br-D & 12L:12D & 13 & $0(0)$ & $92.3(12)$ & $7.7(1)$ \\
T-br-D & 12L:12D & 13 & $0(0)$ & $0(0)$ & $100.0(13)$ \\
T-ma & 18L:6D & 15 & $0(0)$ & $13.3(2)$ & $86.7(13)$ \\
M-br & 12L:12D & 10 & $100.0(10)$ & $0(0)$ & $0(0)$ \\
M-ma & 12L:12D & 13 & $0(0)$ & $0(0)$ & $100.0(13)$ \\
\hline
\end{tabular}
amounts of food in midguts were statistically significant $\left(\chi^{2}=\right.$ 136.6, df $10, P<0.0001$ ).

Similarly, very low levels of the hexameric protein were found in both temperate and Mediterranean males, however, their reproductive status was not determined. In the present paper we found no profound differences between the mating activity of 10-day-old macropterous and reproductive brachypterous males reared under long-day conditions. Finding that macropterous males are sexually active was supported by the immunoreactivity test showing the normal function and differentiation of their AG (in contrast to diapausing brachypterous males) and by the capability of these males to fertilize the eggs laid by reproductive brachypterous females. All these results clearly show that there is no reproductive arrest of nondiapause type in macropterous males as that reported earlier for the macropterous females (Socha \& Šula, 1996). While the pre-oviposition period in macropterous females with reproductive arrest of non-diapause type is considerably longer (19 and 38 days in T-ma and M-ma females, respectively) than in normal reproductive brachypterous females ( 7 days) (Socha \& Šula, 1996), mating activity of 10-day-old macropterous males is already almost as high as in the reproductive brachypterous males of the same age (present results). However, it cannot be excluded that macropterous males may develop mating activities a little later than the reproductive brachypterous ones, though the results of Western blotting five day after emergence were similar between these wing morphs. Anyway, our results revealed sexdependent differences in reproductive status of the macropterous morph of $P$. apterus: while in the females the reproductive arrest of non-diapause type is characterized by the long pre-oviposition period (Socha \& Šula, 1996), no such prolongation of the pre-reproductive period occurs in the males.

Considering the values of photoperiodic regulation of the mating activity of brachypterous bugs (slower induction, faster activation), there is also a higher tendency of $P$. apterus males to remain or become active when compared with females (Hodková et al., 1991). In the brachypterous morph of this bug, the higher tendency to reproductive activity in males than in females was recorded particularly in early autumn (Hodek, 1971). Moreover, it is known that males and females of some insects can differ not only in the tendency to enter diapause, but also in diapause development, the intensity of diapause and in post-diapause development (Danks, 
1987). In some species, females are more likely to enter diapause than males, as in the tick Dermacentor reticulatus (Szymánski \& Černý, 1981), the butterfly Batus philenor (Sims \& Shapiro, 1983) and the mosquito Aedes geniculatus (Sims \& Munsterman, 1983). In most annually eusocial insects, only the females have a diapause (Danks, 1987). In Coccinella septempunctata the activity of the male accessory glands is independent of diapause and females can be fertilized by males kept under diapause conditions (Hodek \& Honěk, 1996).

We found that in contrast to sexual difference in the reproductive activity of the macropterous morph of $P$. apterus, both the females (Socha et al., 1998) and males (this paper) of this wing morph spontaneously cease feeding after a short period of a food intake. Since the corpora allata (CA) of non-diapause starving females of the brachypterous morph of $P$. apterus, reared under a long-day photoperiod, are inhibited via nervous connections from the brain (Hodková, 1982), a similar mechanism of temporary nervous inhibition of CA resulting in the reproductive arrest of non-diapause type can be presumed also in fasting macropterous females. On the contrary, the probable inhibition of CA in fasting macropterous males is not associated with inhibition of reproduction. The present study shows that it does not interfere with the post-imaginal development and function of $\mathrm{AG}$, mating activity and the capability of males to fertilize eggs.

The present results are in accordance with the finding that the sexual behaviour of brachypterous males exposed to artificial starvation is not inhibited (Žd'árek, 1968). According to this author, the sexual instinct does not disappear during starvation; its intensity only decreases after a longer period of starvation in brachypterous males. An appearance of the mating behaviour coincides with the time of release of spermatozoids and activation of $A G$ in males and with the beginning of vitellogenesis in females. Žd'árek's and our findings show that lasting feeding is not essential for the appearance of the mating instinct in both the macropterous and reproductive brachypterous males. On the contrary, unfed females of the brachypterous morph (Žd'árek, 1968) and fasting macropterous females (Socha \& Šula, 1996) were found to be sexually inactive. Separation of feeding and mating behaviour in macropterous males of $P$. apterus might play a significant role in the dispersal and spreading of the genotype for macroptery into another area, despite the lack of food. This presumption is in a good accordance with findings that lack of food and/or mates induces or increases a seasonal flight activity in some heteropterans, e.g. Neacoryphus bicrucis and Oncopeltus fasciatus (Tauber et al., 1986).

In summary, we showed that the method based on the immunoreactivity of AG might be a useful approach that allows us to distinguish the reproductive males from the diapausing ones. The data obtained from immunoblotting, mating and fertility tests showed that sexual activity of the macropterous males from both the temperate and Mediterranean populations is almost as high as that found for reproductively active males of the brachypterous morph. Sexual behaviour of macropterous males from both temperate and Mediterranean populations is normal even if they do not feed. P. apterus thus belongs to the species characterized by the sexual difference in the reproductive activity of the macropterous morph.

ACKNOWLEDGEMENTS. The work was funded from grant no. 206/99/0068 of the Grant Agency of the Czech Republic (RS). The authors thank G.M. Happ for the gift of antibodies and to D. Rienesslová and R. Gutwirthová for their technical assistance.

\section{REFERENCES}

Danks H.V. 1987: Insect Dormancy: An Ecological Perspective. Biology Survey of Canada, National Museum of Natural Sciences, Ottawa, $439 \mathrm{pp}$.

Grimnes K.A., Bricker C.S. \& HAPP G.M. 1986: A monoclonal antibody against an epitope in both the spermatophore and cuticle of Tenebrio molitor. J. Cell Biochem. 10C: 78 pp.

Hodek I. 1968: Diapause in females of Pyrrhocoris apterus L. (Heteroptera). Acta Entomol. Bohemoslov. 65: 422-435.

Hodek I. 1971: Termination of adult diapause in Pyrrhocoris apterus (Heteroptera: Pyrrhocoridae) in the field. Entomol. Exp. Appl. 14: 212-222.

HodeK I. \& HonĚK A. 1996: Ecology of Coccinellidae. Kluwer Academic Publishers, Dordrecht, The Netherlands, 464 pp.

HoDkoví M. 1982: Interaction of feeding and photoperiod in regulation of the corpus allatum activity in females of Pyrrhocoris apterus L. (Hemiptera). Zool. Jb. Physiol. 86: 477-488.

HoDKoví M. 1994: Photoperiodic regulation of mating behaviour in the linden bug, Pyrrhocoris apterus, is mediated by a brain inhibitory factor. Experientia 50: 742-744.

Hodková M., Zieglerová J. \& Hodek I. 1991: Diapause in males of Pyrrhocoris apterus (L.) (Heteroptera) and its dependence on photoperiod and the activity of females. Zool. Jb. Syst. 118: 279-285.

HoNĚK A. 1976: Factors influencing the wing polymorphism in Pyrrhocoris apterus (Heteroptera, Pyrrhocoridae). Zool. $\mathrm{Jb}$. Syst. 103: 1-22.

HONĚK A. 1985: Ecophysiological differences between brachypterous and macropterous morphs in Pyrrhocoris apterus (Heteroptera, Pyrrhocoridae). Acta Entomol. Bohemoslov. 82: 347-354.

JoHnson C.G. 1969: Migration and Dispersal of Insects by Flight. Methuen, London, $763 \mathrm{pp}$

Kodrík D. \& Socha R. 1999: A Mediterranean population of Pyrrhocoris apterus (Heteroptera: Pyrrhocoridae) exhibits wing morph-related differences in adipokinetic response. Eur. J. Entomol. 96: 327-330.

LAEMMLI U.K. 1970: Cleavage of structural proteins during the assembly of the head of bacteriophage T4. Nature (London) 227: 680-685.

SAUNDERS D.S. 1983: A diapause induction-termination asymmetry in the photoperiodic responses of the linden bug, Pyrrhocoris apterus and an effect of near-critical photoperiods on development. J. Insect Physiol. 29: 399-405.

SEdenstücker G. 1953: Die plastiche Modifikation des Flügels von Pyrrhocoris apterus Linné (Hemiptera - Heteroptera, Pyrrhocoridae). Beitr. Entomol. 3: 29-55.

Sims S.R. \& Munstermann L.E. 1983: Egg and larval diapause in two populations of Aedes geniculatus (Diptera: Culicidae). J. Med. Entomol. 20: 263-271.

Sims S.R. \& Shapiro A.M. 1983: Pupal diapause in Battus philenor (Lepidoptera: Papilionidae). Ann. Entomol. Soc. Am. 76: 407-412. 
SLÁMA K. 1964a: Hormonal control of respiratory metabolism during growth, reproduction, and diapause in female adults of Pyrrhocoris apterus L. (Hemiptera). J. Insect Physiol. 10: 283-303.

SLÁMA K. 1964b: Hormonal control of respiratory metabolism during growth, reproduction, and diapause in male adults of Pyrrhocoris apterus L. (Hemiptera). Biol. Bull. 127: 499-510.

SochA R. 1993: Pyrrhocoris apterus (Heteroptera) - an experimental model species: a review. Eur. J. Entomol. 1: 241-286.

SOCHA R. 2001: Latitudinal gradient in wing-morph response to photoperiod in a flightless bug, Pyrrhocoris apterus (L.) (Heteroptera: Pyrrhocoridae). Eur. J. Entomol. (in press)

SochA R. \& KoDrík D. 1999: Differences in adipokinetic responses of Pyrrhocoris apterus (Heteroptera) in relation to wing dimorphism and diapause. Physiol. Entomol. 24: $278-284$.

SOCHA R. \& ŠULA J. 1992: Voltinism and seasonal changes in haemolymph protein pattern of Pyrrhocoris apterus (Heteroptera: Pyrrhocoridae) in relation to diapause. Physiol. Entomol. 17: $370-376$.

Socha R. \& Šlu J. 1996: Differences in haemolymph proteins in relation to diapause and wing dimorphism in Pyrrhocoris apterus (L.) (Heteroptera: Pyrrhocoridae). J. Comp. Physiol. 166B: $382-387$.

Socha R. \& Zemek R. 2000: Locomotor activity in adult Pyrrhocoris apterus (Heteroptera) in relation to sex, physiological status and wing dimorphism. Physiol. Entomol. 25: 383-389.

SOCHA R., ŠULA J. \& ZEMEK R. 1997: Feeding, drinking and digestive enzyme activities in long- and short-day females of Pyrrhocoris apterus (Heteroptera). Physiol. Entomol. 22: 161-169.

Socha R., Šla J. \& Zemer R. 1998: Feeding behaviour, digestive physiology and lipid content in macropterous females of Pyrrhocoris apterus (L.) (Heteroptera: Pyrrhocoridae). Physiol. Entomol. 23: 91-96.

SZYMÁNSKI S. \& ČERNÝ V. 1981: Sex ratio in the tick Dermacentor reticulatus during the spring and autumnal activity. Folia Parasitol. 28: 283-284.
S̆auman I. \& Sehnal F. 1997: Immunohistochemistry of the products of male accessory glands in several hemimetabolous insects and the control of their secretion in Pyrrhocoris apterus (Heteroptera: Pyrrhocoridae). Eur. J. Entomol. 94: 349-360.

Šla J., Kodrík D. \& Socha R. 1995: Hexameric haemolymph protein related to adult diapause in the red firebug, Pyrrhocoris apterus (L.) (Heteroptera). J. Insect Physiol. 41: 793-800.

ŠULA J., SOCHa R. \& ZeMEK R. 1998: Wing morph-related physiological differences in adults of temperate population of Pyrrhocoris apterus (L.) (Heteroptera). Comp. Biochem. Physiol. 121A: 365-373.

Tauber M.J., Tauber C.A. \& Masaki S. 1986: Seasonal Adaptations of Insects. Oxford University Press, New York, $411 \mathrm{pp}$.

Tischler W. 1959: Zur Biologie der Feuerwanze (Pyrrhocoris apterus L.). Zool. Anz. 163: 392-396.

Towbin H., Staehelin T. \& Gordon J. 1979: Electrophoretic transfer of proteins from polyacrylamide gels to nitrocellulose. Procedure and some applications. Proc. Natn. Acad. Sci. U.S.A. 76: 4350-4354.

Zachardová D., Sehnal F. \& Landa V. 1989: Makisterone A content and gonadal development in Pyrrhocoris apterus reared under long versus short photoperiods. In Toner M., Soldán T. \& Bennettová B. (eds): Regulation of Insect Reproduction $I V$. Academia, Praha, pp. 59-71.

Zera A.J. \& Denno R.F. 1997: Physiology and ecology of dispersal polymorphism in insects. Annu. Rev. Entomol. 42: 207-231.

ŽD̆ÁRER J. 1967: Effect of Hormones on the Sexual Behaviour of the Bug Pyrrhocoris apterus L. Ph.D Thesis, Acad. Sci., Praque, 120 pp. (in Czech)

ŽD̆ÁREK J. 1968: Le comportement d'accouplement à la fin de la diapause imaginale et son contrôle hormonal dans le cas de la punaise Pyrrhocoris apterus L. (Pyrrhocoridae, Heteroptera). Ann. Endocrinol. 29: 703-707.

ŽD̆ÁREK J. 1970: Mating behaviour in the bug, Pyrrhocoris apterus L. (Heteroptera): ontogeny and its environmental control. Behaviour 37: 253-268.

Received March 7, 2000; revised July 12 2000; accepted September 20,2000 